\title{
Dificuldades e estratégias de enfrentamento apontadas pela equipe de enfermagem na atuação com dependentes químicos
}

\author{
Teresa Cristina Gioia Schimidt, D.Sc.*, Walter Luiz Teixeira**
}

*Enfermeira, Docente Colaboradora no Departamento Médico Cirúrgico da Escola de Enfermagem da USP, Docente no Departamento de Saúde da Universidade Nove de Julho, Enfermeira da Secretaria de Estado da Saúde de São Paulo. São Paulo/SP, **Enfermeiro, Especialista em Saúde Mental e Psiquiatria pela Universidade Nove de Julho, Supervisor Técnico pela Congregação das Irmãs Hospitaleiras do Sagrado Coração de Jesus, São Paulo/SP

\section{Resumo}

Objetivo: Reconhecer as dificuldades enfrentadas e as estratégias aplicadas pela enfermagem para lidar com os dependentes químicos em diferentes cenários. Método: Pesquisa de campo, transversal, exploratória com abordagem qualitativa realizada com 47 profissionais de enfermagem em uma casa de saúde no município de São Paulo. A coleta dos dados foi feita por meio de um questionário com duas perguntas norteadoras. Resultados: As dificuldades apontadas foram categorizadas em: manipulação; medo; aderência ao tratamento; abstinência; comunicação; normas; capacitação; família; internação involuntária; fissura; terapia ocupacional e revista. As estratégias utilizadas pela enfermagem para superar as dificuldades foram: comunicação; paciência e respeito; desenvolvimento profissional; conhecimento técnico; incentivo ao tratamento e disciplina. Conclusão: Conclui-se que todas as estratégias apontadas podem ser usadas a favor do enfrentamento dos problemas e dificuldades recordadas e que elas são pertinentes em vários locais de trabalho.

Palavras-chave: enfermagem psiquiátrica, profissionais de saúde, dependência química.

\section{Abstract \\ Difficulties and coping strategies identified by nursing staff working with people addicted to drugs}

Objective: To recognise the difficulties faced and the strategies applied by nursing staff in dealing with people addicted to drugs in different scenarios. Method: Cross-cutting, exploratory field research with a qualitative approach undertaken with 47 nursing staff at a health centre in the municipality of São Paulo, Brazil. Data was collected using a questionnaire consisting of two guiding questions. Results: The identified difficulties were categorised into: manipulation; fear; adherence to treatment; abstinence; communication; standards; training; family; involuntary hospitalisation; craving; occupational therapy and monitoring. The strategies used by nursing staff to overcome difficulties were: communication; patience and 
respect; professional development; technical knowledge; incentive to treatment and discipline. Conclusion: It has been concluded that all identified strategies can be positively used in dealing with the recorded problems and difficulties and that they are appropriate for various workplaces.

Key-words: psychiatric nursing, health professionals, drug addiction.

\section{Resumen}

\section{Las dificultades y las estrategias de afrontamiento indicadas por el equipo de enfermería en trabajos con químico dependientes}

Objetivo: Reconocer las dificultades que se le presentan y las estrategias aplicadas por la enfermería para hacer frente a los problemas con adictos a las drogas en diferentes escenarios. Método: Estudio de campo, transversal, enfoque cualitativo exploratorio llevados a cabo con un sondeo a 47 enfermeras en un hospital en São Paulo, Brasil. La recolección de datos se realizó a través de un cuestionario con dos preguntas orientadoras. Resultados: Los problemas observados fueron categorizados en: manejo; miedo; la adherencia al tratamiento; abstinencia; comunicación; normas; capacitación; familia; hospitalización involuntaria; compulsión; terapia ocupacional e inspección. Las estrategias utilizadas por la enfermería para superar las dificultades fueron: comunicación; la paciencia y el respeto; desarrollo profesional; el conocimiento técnico; estímulo al tratamiento y disciplina. Conclusión: Se concluye que todas las estrategias identificadas pueden ser utilizadas para hacer frente a los problemas y dificultades que se presentan, ya que son relevantes en trabajos para la superación de la adicción a drogas.

Palabras-clave: enfermería psiquiátrica, profesionales de la salud, adicción química.

\section{Introdução}

Além das dimensões políticas, sociais, religiosas, culturais e filosóficas, a educação em enfermagem em sua complexidade está relacionada com a prática e teoria da pessoa, família, comunidade e sociedade, indo ao encontro de um dos princípios do Sistema Único de Saúde (SUS), uma vez que as açóes devem contemplar as necessidades do povo, levando em consideração as dificuldades e as individualidades das diferentes abordagens no processo saúde-doença $[1,2]$.

Ao considerar a integralidade do cuidado, a equipe de enfermagem deve estar capacitada para lidar com os diferentes perfis dos clientes. Estudos argumentam que o prisma do cuidado integral à saúde traz o destaque pautado nos modos de interagir com as pessoas, independente de ser na etapa saúde-doença e/ou no cuidado [3].

Atualmente, um dos transtornos que deixa as pessoas mais debilitadas está relacionado ao consumo de álcool e outras substâncias psicoativas pela consequente compulsividade. $\mathrm{O}$ descontrole no uso de bebidas alcoólicas exerce um efeito destruidor na saúde do ser humano, prejudicando sobremaneira seu convívio social e suas relaçóes [4].

Sabe-se que muitas universidades vêm priorizando a introdução de disciplinas integradoras nos cursos de graduação, entretanto a real aplicabilidade com cunho alicerçado na integralidade e na multidisciplinaridade está aquém do esperado, pois, em algumas etapas do processo de formação, o cuidado é remetido ao modelo antigo, ou seja, o biomédico, no qual se dá ênfase à doença propriamente dita em detrimento do sujeito, que é o foco do cuidado [5].

No passado, é interessante mencionar que a assistência de enfermagem psiquiátrica impunha disciplina nos comportamentos tidos como anormais, contudo, de algumas décadas para cá passa, por uma mudança e/ou ressignificação, as instituições psiquiátricas estão lentamente sendo substituídas por outras unidades de atenção à saúde. Cabe ressaltar que, tanto na psiquiatria como na saúde mental e na dependência química, estas questóes influenciam os formandos que lidam diretamente com uma população subjetiva, embora o modelo técnico-assistencial ainda vigore na formação dos profissionais de saúde [6].

No mundo contemporâneo, no lado ocidental do planeta, onde predomina a sociedade capitalista, diariamente, testemunha-se a droga (uso de), como um dos temas principais das mídias. Vários profissionais da saúde, como por exemplo, médicos, psicólogos, entre outros, são convocados para discorrer sobre o tema, pois, o consumo de subs- 
tâncias mais conhecidas, como as "psicoativas" não é somente um problema de saúde, mas também de segurança pública. Por outro lado, pode-se verificar que há uma discrepância entre o real e o formal; por muitas décadas, a formação profissional tratava o problema de forma superficial, náo integrada e muitas vezes, incentivava os profissionais de saúde a manterem uma visão prática, baseada na concepção de crenças e julgamentos de valor, o que acabava por provocar a realização de procedimentos e/ou abordagens inadequados e pautados em uma postura pouco inclusiva e em desacordo com a ética esperada e desejada $[7,8]$.

Os dependentes de substâncias psicoativas possuem necessidades específicas, sejam elas derivadas da própria dependência e/ou de problemas que danificam a saúde diretamente, daí a necessidade do enfermeiro estar preparado e apto para reconhecer e prestar os devidos cuidados. Estudos apontam que o modo de agir dos profissionais de saúde vem se constituindo em um dos pontos de dificuldade que precisam ser enfrentados, além do manejo do dependente químico, o que tem levado a acreditar que tenha correlação com o tipo de formação recebida desde a graduação, por esses profissionais [4].

Ao analisar os problemas de saúde, as drogas vêm assumindo um papel de destaque, por isso, cabe aqui defender como primordial uma capacitação adequada dos profissionais que atuam nesse contexto. O enfermeiro aparece com o papel de promoção e educação em saúde que tenha um embasamento técnico-científico adequado, para tal, só é possível com a introdução da temática pertinente na graduação [8].

Ao trazer a discussão da dependência química nos dias de hoje, é inerente colocar em pauta a questão do processo saúde/doença, sendo independente discutir os termos referentes a conceitos de formação e de atuação dos profissionais na área da saúde, levando em consideraçáo o tratamento e a promoçáo da saúde. Os conceitos sobre saúde, doença e, até mesmo, o consumo de drogas, irrevogavelmente, foram influenciados diretamente pelo contexto histórico, social e cultural da época, até porque questóes como estas sempre estiveram presentes na vida do homem [9]. Considerando que o enfermeiro é o profissional responsável pela equipe de enfermagem, uma de suas principais prerrogativas é a devida assistência de enfermagem, independente da clínica, portanto, cabe a esse profissional levantar os problemas e/ou dificuldades de sua equipe e elaborar um planejamento estratégico que contemple todas as necessidades da equipe, pois, estes profissionais vão atuar diretamente com os pacientes dependentes químicos, logo, precisam estar aptos a lidar com as mais diversas situaçóes e procurar resolvê-las do melhor modo possível, sem que haja prejuízo para o cliente nem ao profissional, tornando com isso um relacionamento tranquilo, seguro e confiante para ambos.

Diante do exposto acima, emergem as seguintes inquietaçóes: Como a equipe de enfermagem vem lidando e trabalhando com usuários de álcool e outras drogas psicoativas dentro de uma clínica de dependentes químicos? Quais as dificuldades que enfrenta nesse cenário? Quais as estratégicas que precisa utilizar para atuar com qualidade nos diferentes cenários em que está presente o dependente químico?

As hipóteses estão pautadas em considerar que os problemas e/ou dificuldades estáo majoritariamente relacionados ao acontecimento técnico-científico, à falta de experiência do enfermeiro ao lidar com dependentes químicos è̀s dificuldades na atuação em emergências clínicas.

Justifica-se o desenvolvimento da pesquisa, uma vez que conhecer as dificuldades que os profissionais da equipe de enfermagem encontram para atuar na dependência química (DQ) poderá nortear o enfermeiro da unidade a elaborar programas e açóes com intuito de minimizar as dificuldades de sua equipe.

Esta pesquisa teve como objetivos reconhecer as dificuldades enfrentadas e as estratégias aplicadas pela enfermagem para lidar com os dependentes químicos nos diferentes cenários.

\section{Material e métodos}

Trata-se de uma pesquisa de campo, transversal, exploratória, com abordagem qualitativa sendo desenvolvida em uma casa de saúde, de caráter filantrópico no município de São Paulo. A amostra foi composta por 47 profissionais de enfermagem, sendo, dez enfermeiros, oito técnicos de enfermagem e 29 auxiliares de enfermagem, representando $76,9 \%, 72,7 \%$ e $55,8 \%$ do total de quadro de $\mathrm{RH}$, respectivamente, que obedeceram aos seguintes critérios: possuírem idade igual ou superior a 18 anos; serem contratados pela instituiçáo; que estivessem no dia da coleta de dados em horário de trabalho; aceitassem, após a explicação dos objetivos e da 
metodologia do trabalho, participar do estudo assinando voluntariamente o termo de consentimento livre e esclarecido (TCLE).

Ressalta-se que os profissionais que náo concordaram em participar, bem como os que estavam de férias ou licença-médica no período da coleta dos dados foram excluídos do estudo.

A coleta dos dados foi realizada por meio de um questionário com perguntas próprias para caracterização da amostra e duas perguntas norteadoras. A primeira pergunta: "cite três dificuldades principais que você enfrenta em seu dia a dia para que atenda com qualidade aos pacientes dependentes quimicos?". E a segunda: "o que você faz para conseguir enfrentar suas dificuldades e trabalhar com qualidade?".

A coleta ocorreu no local de trabalho do entrevistado, mais precisamente, na sala da chefia de enfermagem, individualmente, com um tempo de duração de, aproximadamente, 15 minutos em todos os períodos, ou seja, manhã, tarde e noite.

Para garantir o anonimato dos entrevistados, os enfermeiros foram identificados com a letra "e", os técnicos de enfermagem pela letra " $t$ " e os auxiliares de enfermagem pela letra "a", seguido do número sequencial, conforme as entrevistas.

Ratifica-se que toda a pesquisa está em consonância com a resoluçáo 446 de 12 de dezembro de 2012 que prevê as condiçóes éticas necessárias que precisam ser respeitadas quando se lida com seres humanos. A referida pesquisa náo ofereceu qualquer tipo de risco nem incidiu nenhum ônus à unidade ou ao entrevistado.

O tratamento dos dados foi realizado em sua organização, por meio da digitação das respostas no programa Word e, posteriormente, lidos e as categorias criadas, conforme Minayo [10].

\section{Resultados}

Em relação ao gênero e idade, 11 eram homens $(23,4 \%)$ com idade média de 37,8 anos; 36 mulheres $(76,6 \%)$ com idade média de 40,1 anos. A variação geral de idade - independente do gênero - ficou em 39,6 anos.

Quanto ao tempo de instituição, nove dos homens $(81,8 \%)$ tinham uma média de 5,4 anos e dois dos pesquisados $(18,2 \%)$ estavam no período de experiência; no que se refere às mulheres, 34 $(94,4 \%)$ tinham uma média de 8,7 anos e duas $(5,6 \%)$ estavam em período de experiência; a média geral do tempo na instituição - independente do gênero - atingiu 8 anos entre os 43 pesquisados $(91,5 \%)$, e quatro $(8,5 \%)$ encontravam-se no período de experiência.

Entre os enfermeiros somente sete (70\%) mulheres possuíam alguma especializaçáo, verificou-se que elas estavam relacionadas à área de saúde mental, psiquiatria e/ou dependência química.

Tanto as falas que apontaram as dificuldades como as estratégias utilizadas pela equipe de enfermagem no enfrentamento do convívio e do cuidado com dependentes químicos foram categorizadas, conforme se apresentam.

As dificuldades puderam ser categorizadas em 12 distintas, podendo uma mesma fala pertencer a uma ou mais categorias.

A categoria manipulaçáo 18 (38,3\%) incorporou os discursos relacionados à tentativa de manipulação quando da abstinência, e a própria dificuldade em lidar tão somente com a manipulação, uma vez que é uma característica bem marcante nos dependentes químicos. Os exemplos dos discursos foram:

"Manipulação no momento da abstinência" (t 8).

"Bom, no curso, foi passada pouca coisa para os alunos lidarem com abstinência e as solicitações. Eles são pacientes manipuladores" (a 6).

"lidar com comportamento manipulador do mesmo" (t 6).

Já o medo $21(44,7 \%)$ foi a categoria que agregou as falas relacionadas à segurança necessária imposta pela realidade, bem como a presença de hostilidade e agressividade. Eis algumas falas que podem exemplificar:

"Às vezes, eu tenho medo do que eles possam fazer com o próximo" (t3).

"A presença de hostilidade, agressividade e do humor disfórico são coisas que dificultam um pouco" (e 3).

"Segurança no ambiente no físico, não se tem aqui segurança (profissional)” (t 1).

A categoria aderência ao tratamento 12 $(25,5 \%)$ reuniu as falas que recordaram as dificul- 
dades comumente presentes ligadas à resistência, descompromisso, recaída e negligência dos retornos. Eis os exemplos:

"Lidar com a falta de comprometimento do paciente com seu próprio tratamento" (e1).

"A resistência no tratamento, sua recaída e esquecimento do retorno à instituição" (e4).

"Pacientes são resistentes ao tratamento" (e 5).

A categoria abstinência 7 (14,9\%) agrupou as falas, cuja preocupação é lidar com os dependentes no momento em que a mesma acontece, bem como seu período e/ou fase, independente da droga usada. Os discursos constituem os exemplos:

"Abstinência" (a 2).

"Abstinência de qualquer que seja sua adicção (droga de escolha)" (a 8).

"Período de abstinência" (e 2).

$\mathrm{Na}$ comunicação 6 (12,8\%), foi possível observar os discursos que citam a falha na comunicação entre os profissionais; entre os profissionais e os pacientes - questóes da própria linguagem - e também entre a equipe multiprofissional, bem como a maneira de realizar a abordagem, pois é prejudicada em razão dos pacientes trazerem consigo um vocabulário carregado de gíria. São exemplos os discursos:

"Falta de comunicação entre a equipe multiprofissional" (e 1).

"A forma de abordagem, a maneira de se comunicar, pois eles têm outra forma de comunicação através de gírias" (a 28).

"A minha principal dificuldade é a abordagem e o manejo com este paciente" (t 4).

A categoria normas $6(12,8 \%)$ foi composta pelas citaçōes que recordaram a falta de aceite da normatização existente e a dificuldade que possuem para aceitarem a negativa de um pedido. Eis os exemplos:
"Como conseguir que entendam a palavra não” (t 3).

"De aceitar, as normas da instituição" (a 3).

"Fazer com que elas aceitem o não" (a 12).

A categoria capacitação $4(8,5 \%)$ reuniu as falas que agregam a capacitação no sentido técnico, a capacitação no sentido da instituição investir na mesma, como também profissionais mais preparados. Os exemplos dos discursos são:

$$
\begin{aligned}
& \text { "Embasamento técnico" (e 2). } \\
& \text { "Capacitação pouco investimento" (e 9). } \\
& \text { "Mais profissionais qualificados para traba- } \\
& \text { lhar com esses pacientes" (a 2). }
\end{aligned}
$$

Outra categoria citada foi a família $4(8,5 \%)$, uma vez que os discursos apontaram que a presença da família ajuda e sua ausência torna o ambiente constrangedor. Seguem os exemplos:

$$
\begin{aligned}
& \text { "Falta da família” (a 2). } \\
& \text { "Incontingência familiar" (e 7). } \\
& \text { "E a questão da família que também entra } \\
& \text { como uns dos pontos que muito ajuda e } \\
& \text { algumas não querem nem saber mais, e é } \\
& \text { uma situaçáo muito constrangedora” (a 18). }
\end{aligned}
$$

A categoria internação involuntária 4 (8,5\%) reuniu os discursos que apenas citam a categoria, $\mathrm{e}$ outros que veem como um dificultador, visto que a não aprovação do paciente não está instrínseca, assim, causando sua revolta. Os exemplos são:

"As internações involuntárias" (e 2).

"Com a internação involuntária, corremos o risco de ser agredida, pois o mesmo vem enganado, é necessário logo tomar as atitudes cabíveis" (t 1 ).

"Dificuldade com pacientes com internação involuntária” (a 7). 
A categoria fissura $4(8,5 \%)$ agregou as falas sobre o momento da fissura, a categoria também é citada, até mesmo, embora o início da fala negue dificuldade. Os exemplos são:

"No momento em que estão na fissura" (a $15)$.

"Particularmente nenhuma, porém, quando o paciente está com fissura, abstinência e com vontade de ir embora, fica mais difícil de lidar com ele" ( $\mathrm{t} 2$ ).

"Quando o paciente está no momento da fissura/abstinência quaisquer que seja sua dicção (droga de escolha)" (a 8).

A categoria terapia ocupacional 2 (4,3\%) acumulou os discursos não só sobre a carência de atividades, como também uma diversificação maior delas, tanto física como terapeuticamente. Os exemplos são:

"Mais atividades diárias" (a 25).

"Atividades para os mesmos (físicas e terapêuticas)” (a 27).

A categoria revista 2 (4,3\%) agrupou discursos que apontaram a dificuldade em razáo da entrada de drogas dentro da unidade. Os exemplos são:

"Supervisionar com mais detalhes em revistas para evitar entrada de entorpecentes" (a 24).

"Vistoria voltada ao paciente referente ao ato de internação em entrada com droga" (e 10).

As dificuldades relatadas foram muitas, entretanto, foi observado que três $(6,4 \%)$ dos profissionais da equipe de enfermagem alegaram não possuir qualquer tipo de dificuldades.

As estratégias apontadas para o enfrentamento das dificuldades ao lidar com os pacientes dependentes químicos foram categorizadas em seis distintas. Ressalta-se que uma mesma fala pode pertencer a uma ou mais categorias.

A comunicação $36(76,6 \%)$ foi a mais citada, sendo a categoria que reuniu as falas que ratificam que a comunicação é essencial, primordial, pois, sendo feita de modo adequado transmite segurança ao paciente, facilita o esclarecimento sobre as normas da instituição, melhora a abordagem, colabora a favor do entrosamento da equipe, dentre outras. Abaixo, seguem alguns discursos que podem exemplificar:

\section{"Comunicação é fundamental para esclarecer normas e rotina onde o mesmo encontra-se em tratamento" (e 5). \\ "É tentar transmitir segurança para eles; ser firme nas respostas e postura" (t 1$)$. \\ "Ouvi-los, cada um deles, dando-lhes aten- ção, tentando entendê-los e lhe mostrar as coisas boas que a vida lhe oferece" (a 2).}

A categoria paciência e respeito 11 (23,4\%) agrupou os discursos sobre a importância da calma e paciência, manutençáo do autocontrole no ambiente de trabalho no momento das múltiplas solicitaçóes demandadas pelos pacientes, ainda, o respeito como recurso facilitador para um bom vínculo, estabelecimento de vínculo e confiança e o, consequente, favorecimento de um ambiente agradável. São alguns exemplos:

"A paciência é um dos principais pontos que encontro para lidar com os pacientes e situaçôes difíceis que ocorrem" (a 1).

"Responsabilidade no que faz, no ambiente de trabalho, passar segurança para as pacientes e ter muita paciência e calma” (t 5 ).

"Procurar sempre respeitar os problemas e as dificuldades dos pacientes, sempre focando o conhecimento e aprendizado para melhorar no dia a dia" ( a 26).

$\mathrm{Na}$ categoria desenvolvimento profissional 7 $(15,0 \%)$, os discursos permearam o lado profissional, a capacidade do profissional transformar as dificuldades em oportunidades, fortalecer o vínculo com a própria profissão e também o fato de não deixar que os problemas pessoais prejudiquem a assistência e colaborem para um ambiente melhor de ser trabalhado. Os exemplos são:

\footnotetext{
"Tentar usar o lado profissional, deixando o paciente entender que ele está aqui apenas para tratamento" (t 8).
} 
"Não deixar seus problemas familiares interferirem no seu trabalho, mostrar que tem segurança e pulso firme" ( $\mathrm{t} 7$ ).

"Devemos fazer as dificuldades novas oportunidades para fazer um trabalho com qualidade, e ser prestativo, saber usar assistência para que haja uma boa recuperação a esses pacientes, e principalmente fazer o que gosta para ter um ótimo desenvolvimento" (a 18).

Já a categoria conhecimento técnico 4 (8,5\%) agregou as falas de buscar especializaçóes, agregar capacitações, entre outras. Seguem os discursos que a exemplificam:

"Se aprofundar mais na especialidade dentro do que pede a necessidade dentro da instituição para melhor poder atender as internas e tentar trazê-las para sua realidade e convívio após a abstinência" (e 4).

"Procuro me capacitar sempre para atender o paciente com humanizaçáo, participando de palestras, convençôes, treinamentos; lendo livros, fazendo pesquisa e, assim, por diante" (a 1).

"Embasamento técnico" (e 2).

Quanto à categoria incentivo ao tratamento $3(6,4 \%)$ reuniu os discursos de sensibilização à aderência ao tratamento, tanto o medicamentoso como o terapêutico, mas também de sociabilização. Os exemplos dos discursos são:

"Procuro atender suas necessidades, de acordo com as minhas atribuiçôes, dialogando com o mesmo, mostrando os benefícios que ele terá ao aceitar o tratamento terapêutico e medicamentoso, que possa, ao sair de alta hospitalar, mostrar para si mesmo, sua família e a sociedade que está pronto para ter uma vida como cidadáo, com seu trabalho, sua família e poder ajudar outros no mesmo problema que ele enfrentou e continuar a jornada com grupo de apoio seja AA, NA, dentre outros" (a 8).

"Saber a hora de cobrar e expor onde o mesmo está errando na conduta; que não está lá fora, mas veio para tentar se sociabilizar novamente" ( $\mathrm{t} 1$ ).

"Procuro observar algumas atividades que acontecem no setor e explico a importância para participaçáo" (e 8).

A categoria disciplina $3(6,4 \%)$ reuniu as falas, cujas regras e limites são ferramentas importantes para que os profissionais consigam trabalhar adequadamente e que a instituição tenha as suas regras. Exemplificam os discursos:

"Sempre orientar o paciente que tem de manter o respeito com os colaboradores do setor" (a 21).

"Colocar regras e limites na forma que eles possam entender que não é o lado pessoal mais a regra da entidade" ( $\mathrm{t} 1$ ).

"Tento colocar para os pacientes que a disciplina é importante e é preciso seguir normas e rotinas" (e 8).

\section{Discussão}

$\mathrm{Na}$ atualidade, a dependência química, além de ser um grave problema de saúde pública, vem provocando os profissionais de saúde no sentido de entenderem o perfil do dependente de substâncias psicoativas para minimizarem as dificuldades, tanto na abordagem como no manejo dos problemas relacionados aos usuários [11].

Além dos impactos que ocorrem decorrentes do uso abusivo de substâncias, é importante ressaltar sentimentos vividos pelos familiares, como por exemplo, o medo da violência que a família possa vir a sofrer, muitas vezes dentro do próprio lar e não somente as agressóes físicas, como também as psicológicas, o sentimento de raiva, culpa e vergonha (da família) por possuir entre ela um dependente químico. Estes sentimentos podem ser oriundos da relação de codependência; concomitante a isso existem o desgaste emocional e o físico que podem trazer um quadro patológico à família [12].

No tratamento da dependência química, não se pode deixar de lado a questão da adesão ou não do dependente químico, isso ainda é um dos desafios, mas, independente do tipo de tratamento a que se 
submete o dependente - adolescentes, em particular -, é correto afirmar que o tratamento que náo prevê a participação ativa do dependente, com uma escuta profissional qualificada, poderá desencadear mais complicaçóes do que aderência [13].

Destaca-se o fato da aderência no tratamento, pois esta se modifica, de acordo com o tipo de substância consumida. Constata-se que a adesão ao tratamento é um desafio a ser vencido, em razão do alto índice de abandono diretamente proporcional, relacionado aos dependentes químicos usuários de crack, portanto, é necessário traçar um planejamento de cuidados direcionado a essa população, considerando as particularidades dos mecanismos de ação da droga e suas consequências [14].

Em pesquisa realizada com 16 enfermeiros de 13 CAPS da cidade de São Paulo, verificou-se que os dependentes químicos devem ser tratados como pessoas que sofrem de uma doença, somando-se ainda o fato de serem pessoas que não possuem limites e manipuladoras, cabendo aos mesmos a responsabilidade pela doença [15].

Os relatos acima ratificam as dificuldades de aderência ao tratamento e a manipulaçáo observada nos discursos.

Diante das dificuldades listadas, algumas estratégias são utilizadas pelos profissionais para superá-las, objetivando sempre o sucesso do tratamento.

A família pode ser entendida como um fator protetor ou um fator de risco. Assim, uma família presente, acolhedora, que impóe regras norteadoras, que usa uma comunicaçáo apropriada, que trata com carinho e amor, com certeza, será um fator protetor; caso contrário, ou seja, uma família distante, que não demonstra amor e afeto, ausente, sem diálogo, poderá induzir ao uso de drogas e até mesmo à dependência química [16].

Conforme os dados coletados nesta pesquisa, ficou claro que a comunicação é extremamente importante e foi apontada pelos profissionais de saúde sendo a estratégia mais utilizada para superar as dificuldades.

Sugere-se elaborar uma maneira de atender às demandas, nas quais todos os profissionais da equipe possam chegar a um consenso sobre o rumo de um determinado tratamento, levando em consideraçáo a humanização do mesmo, ainda que o modelo de gerenciamento tenha de ser rediscutido no sentido de criar espaços para uma gestão compartilhada, aumentando os relacionamentos interpessoais e a transversalidade entre os profissionais, para que cada um possa sentir-se como um dos atores principais, devidamente respeitado e valorizado independente do cargo que ocupa [17].

\section{Conclusão}

Diante do objetivo proposto, foi possível listar as dificuldades relatadas pela equipe de enfermagem, bem como reconhecer as estratégias utilizadas para lidar com os dependentes químicos em vários cenários.

Dentre as dificuldades, a manipulação e o medo aparecem com maior incidência. Isso pode ser produto dos pacientes encontrarem-se dentro de um ambiente fechado, cujo tratamento requer do dependente químico que passe por uma série de etapas, em que pode apresentar transtornos, alucinaçóes, delirium e, às vezes, poder ficar agressivo; acrescenta-se a isso, as internaçóes involuntárias e compulsórias, na qual o dependente é levado à unidade contra sua vontade.

A falta de aderência ao tratamento gera dificuldades relacionadas à ambivalência do paciente, pois, em alguns momentos quer o tratamento e de uma hora para outra náo quer mais. Muitas vezes, eles aceitam, pois, apresentam um quadro de saúde deplorável e táo logo apresentam melhora, abandonam o tratamento por se acharem que já estão "curados".

Todas as estratégias apontadas podem ser usadas a favor do enfrentamento dos problemas e dificuldades recordadas, e elas são pertinentes em vários locais de trabalho, que vão além da enfermagem do local pesquisado.

Talvez os achados pudessem ser diferentes se fossem comparados por escolaridade (nível superior e técnico), uma vez que o prisma das categorias certamente seria, no mínimo, algo diferente, este talvez seja um limitante do presente estudo e, ao mesmo tempo, uma ideia a ser desenvolvida nas próximas pesquisas.

O manejo com dependentes químicos ainda requer outros estudos, já que esta pesquisa é apenas uma amostra de uma única unidade, concomitante a isso, alia-se às políticas públicas, baseada na reforma psiquiátrica que ainda está se consolidando no Brasil e necessita do esforço de vários profissionais. Nesse cenário, a equipe de enfermagem tem destaque, uma vez que está diariamente em contato com os dependentes e pode e deve ter um olhar diferenciado. Embasada no conhecimento técnico-científico e na experiência do dia a dia, pode criar estratégias e apri- 
morar as que já são colocadas em prática, visando a um atendimento mais qualificado, humanizado e hospitaleiro, que são as filosofias da instituição, pois cada ser humano é único e necessita ser tratado de diferentes maneiras mesmo que o problema e/ou o tipo de dependência seja o mesmo.

Os resultados poderão ser utilizados no sentido de nortear os enfermeiros a traçarem um planejamento estratégico de educação continuada com objetivo de minimizar as dificuldades e potencializar as estratégias utilizadas pela equipe.

\section{Referências}

1. Salci MA, Maceno P, Rozza SG, Silva DMGV, Boehs AE, Heidemann ITSB. Health education and its theoretical perspectives: a few reflections. Texto Contexto Enferm 2013;22(1):224-30.

2. Silva KL, Sena RR. Integralidade do cuidado na saúde: indicaçóes a partir da formaçáo do enfermeiro. Rev Esc Enferm USP 2008;42(1):48-56.

3. Mello DF, Lima RAG. O cuidado de enfermagem e a abordagem Winnicottiana. Texto Contexto Enferm 2010;19(3):563-9.

4. Rocha FM, Vargas D, Oliveira MAF, Bittencourt MN. Cuidar de dependentes de substâncias psicoativas: percepções dos estudantes de enfermagem. Rev Esc Enferm USP 2013;47(3):671-7.

5. Lima MM, Reibnitz KS, Prado ML, Kloh D. Integralidade como princípio pedagógico na formação do enfermeiro. Texto Contexto Enferm 2013;22(1):106-13.

6. Reinaldo AMS, Pillon SC. História da enfermagem psiquiátrica e a dependência química no Brasil: atravessando a história para reflexão. Esc Anna Nery 2007;11(4):688-93.

7. Ribeiro CT. Que lugar para as drogas no sujeito? Que lugar para o sujeito nas drogas? Uma leitura psicana- lítica do fenômeno do uso de drogas na contemporaneidade. Ágora (RJ) 2009;12(2):333-46.

8. Lopes GT, Lemos BKJ, Lima HB, Cordeiro BRC, Lima LSV. Concepçóes de acadêmicos de enfermagem sobre usuários de drogas. Rev Bras Enferm 2009;62(4):518-23.

9. Pratta EMM, Santos MA. O processo saúde-doença e a dependência química: interfaces e evolução. Psicologia: teoria e pesquisa 2009;25(2):203-11.

10. Minayo MCS, Deslandes SF, Gomes R. Pesquisa social: teoria, método e criatividade. $26^{\mathrm{a}}$ ed. Petrópolis: Vozes; 2007.

11. Guimarães CF, Santos DVV, Freitas RC, Araújo RB. Perfil do usuário de crack e fatores relacionados à criminalidade em unidade de internação para desintoxicaçáo no hospital psiquiátrico São Pedro de Porto Alegre (RS). Rev Psiquiatr 2008;30(2): 101-8.

12. Maciel LD, Zerbetto SR, Filizola CLA, Dupas G, Ferreira NMLA. Consequências e dificuldades da dependência química no âmbito familiar: uma revisão de literatura. Rev APS 2013;16(2):187-96.

13. Scaduto AA, Barbieri V. O discurso sobre a adesão de adolescentes ao tratamento da dependência química em uma instituição de saúde pública. Ciênc Saúde Coletiva 2009;14(2):605-14.

14. Ferreira ACZ, Capistrano FC, Maftum MA, Kalinke LP, Kirchhof ALC. Caracterização de internaçóes de dependentes químicos em uma unidade de reabilitação. Cogitare Enferm 2012;17(3):444-51.

15. Vargas D, Bittencourt MN, Rocha FM, Oliveira MAF. Representação social de enfermeiros de centros de atenção psicossocial em álcool e drogas (CAPS ad) sobre o dependente químico. Esc. Anna Nery 2013;17(2):242:48.

16. Paz FM, Colossi PM. Aspectos da dinâmica da família com dependência química. Estudos de psicologia 2013;18(4):551-8.

17. Cardoso CG, Hennington EA. Trabalho em equipe e reunióes multiprofissionais de saúde: uma construção à espera pelos sujeitos da mudança. Trab Educ Saúde 2011;9(supl.1):85-112. 